\section{SOLITAIRE STENT IN THE TREATMENT OF ACUTE ISCHEMIC STROKE WITH LARGE CEREBRAL ARTERY OCCLUSION}

Objective To investigate the effect of mechanical thrombectomy with solitaire stent in the treatment of acute ischemic stroke with large cerebral artery occlusion. Methods Fifteen acute ischemic stroke patients with a proximal intracranial occlusion in the anterior circulation were included within 6 hours after symptom onset (unknown time of onset allowed in wake upstroke). Patients with a large infarct core or poor collateral circulation on computed tomography $(\mathrm{CT})$ and $\mathrm{CT}$ angiography were excluded. All patients were measured by the National Institutes of Health Stroke Scale (NIHSS) before and 24 hours after the procedure. The primary outcomes were reperfusion at 24 hours and a Thrombolysis in Cerebral Infarction ( $\mathrm{TICl}$ ) score of $2 \mathrm{~b}$ or 3 indicates successful reperfusion. Secondary outcomes included the functional score on the Modified Rankin Scale(MRS) and NIHSS score at 90 days. Good Functional Outcome (GFO), is defined as mRS0-2 at 90 days. Results The preoperative $\mathrm{TICl}$ grading of these 15 patients were all level 0.14 patients were level $2 \mathrm{~b}$ to level 3 after the thrombectomy, 1 ipsilateral cervical carotid occlusion patient failed recanalization.14 patients with reperfusion at 24 hours showed good early neurologic improvement. The MRS score of all the 14 patients were $<2$ point at 90 days There were no obvious adverse reactions and complications in these patients after mechanical thrombectomy. Conclusion The application of mechanical thrombectomy with solitaire stent for the treatment of acute ischemic stroke with large cerebral artery occlusion is safe and time-efficient, which could improve the recanalization rate, decrease or even eliminate the application of thrombolytic drugs and reduce the rate of intracranial hemorrhage. Awake stroke patient can also benefit from thrombectomy.

Keywords

- acute ischemic stroke • large cerebralartery occlusion $•$ mechanical thrombectomy • solitaire stent

\section{Introduction}

It has been reported that each year, more than 530000 individuals have a first acute ischemic stroke, and an additional 160000 have a recurrent ischemic stroke in the United States [1]. Recent progress has been reported of a new-generation stent that can reduce the longterm impact of acute ischemic stroke caused by large-vessel occlusion [1].

The middle cerebral artery and internal carotidartery have acute occlusion leading to a large area cerebral infarction, which leads to high morbidity and mortality [2-3]. At present, the solitaire stent system approved by the United States Food and Drug Administration recanalization device [4-7]. Our present study uses solitaire stent in treating acute intracranial vascular occlusion and demonstrates positive effects, as the following reports. (FDA) is the main endovascular mechanical

\section{Materials and methods}

\section{Patients}

Fifteen cases of acute ischemic stroke patients were enrolled at our hospital in February 2014 to February 2015. Written informed consent from all patients was obtained prior to participation in the study. All patients aged $\leq 80$ years who had undergone mechanical thrombectomy for the treatment of acute ischemic stroke were identified. In summary, our selection criteria for patients receiving mechanical thrombectomy included significant deficit (NIHSS 6 or severe focused deficit such as complete loss of function in one extremity or aphasia), less than $6 \mathrm{~h}$ from symptom onset if known (unknown time of onset allowed in wake upstroke) and demonstration of no significant large infraction or hemorrage in non-contrast computed tomography (CT). Patients with a large infarct core or poor collateral circulation on computed
Wenbao Liang*

Zhijie Ou,

Rui Luo

Department of Neurology Karamay Central Hospital Karamay, P.R. China
Received 17 April 2017 accepted 16 August 2017

tomography (CT) and $\mathrm{CT}$ angiography were excluded. Eligible patients had an occlusion of the distal intracranial carotid artery, middle cerebral artery (M1), ipsilateral cervical carotid occlusion, established with computed tomographic (CT) angiography (CTA), magnetic resonance angiography (MRA), or digitalsubtraction angiography (DSA). Included were patients with an intracranial carotid artery dissection.

The baseline characteristics and process measures are shown in Table 1. In summary, demographic characteristics include a median of age was $66 \mathrm{yr}$ (Interquartile range,5576yr), with 5 females. Medical history includes, 12 patients with hypertension, 6 patients with diabetes mellitus, 2 patients had atrial fibrillation. Clinical characteristics demonstrate, a median NIHSS score of 17 (Interquartile range,14-20). The median for systolic blood pressure at hospital arrivalwas 145 
$\mathrm{mmHg}$ (Interquartile range,128-163mmHg). The imaging characteristics include, a median of ASPECTS on CT were 9 (Interquartile range,8-10). Location of occlusion on CTA or DSA demonstrate13 patients on the M1 middle-cerebral-artery segment, 2 patients with ipsilateral cervical carotid occlusion. Process times show the median time of stroke onset to emergency care was $165 \mathrm{~min}$ (Interquartile range,115-300 $\mathrm{min}$ ), the median time of stroke onset to study CTwas $185 \mathrm{~min}$ (Interquartile range,145-340 $\mathrm{min}$ ), the median time of study $\mathrm{CT}$ to groin puncturewas $45 \mathrm{~min}$ (Interquartile range,38-60 $\mathrm{min}$ ), and the median time of study $\mathrm{CT}$ to first reperfusionwas90min(Interquartile range,65-110 $\mathrm{min}$ ).

\section{Thrombectomy}

Intra-arterial treatment consisted of arterial catheterization with a microcatheter to the level of occlusion and delivery of a mechanical thrombectomy. The method of intra-arterial treatment was left to the discretion of the local interventionist. Mechanical treatment was a retrievable solitaire stent $(4 \mathrm{~mm} \times 20 \mathrm{~mm}$; EV3 company), the device that had received U.S. Food and Drug Administration approval or a Conformité Européenne (CE) marking and was approved by the steering committee to be used in the trial. The abbreviation of $\mathrm{TICl}$ (Thrombolysis in Cerebral Infarction) denotes modified Treatment in Cerebral Ischemia classification, with scores ranging from 0 (no flow) to 3 (normal flow), $2 b$ is nearly normal flow.

All patients were measured by the National Institutes of Health Stroke Scale (NIHSS) before and 24 hours after the procedure. The primary outcomes were reperfusion at 24 hours and a $\mathrm{TICl}$ score of $2 \mathrm{~b}$ or 3 indicates successful reperfusion. Secondary outcomes included the functional score on the modified Rankin scale (MRS) and NIHSS score at 90 days. Good functional outcome (GFO), defined as mRSO-2 at 90 days.

\section{Statistical analysis}

Statistical analysis was performed using stata12.0 statistical software(http://www.stata. com; Stata Corporation, College Station, TX). The results are expressed as the mean \pm S.D.
Table 1. Baseline Characteristics and Process Measures*

\begin{tabular}{|c|c|}
\hline Variable & Thrombectomy $(\mathrm{N}=15)$ \\
\hline \multicolumn{2}{|l|}{ Demographic characteristics } \\
\hline \multicolumn{2}{|l|}{ Age $-y r$} \\
\hline Median & 66 \\
\hline Interquartile range & $55-76$ \\
\hline Female sex — no. (\%) & $5(33.3)$ \\
\hline \multicolumn{2}{|l|}{ Medical history — no. (\%) } \\
\hline Hypertension & $12(80)$ \\
\hline Diabetes mellitus & $6(40)$ \\
\hline Atrial fibrillation & 2(13) \\
\hline \multicolumn{2}{|l|}{ NIHSS scoreł } \\
\hline Median & 17 \\
\hline Interquartile range & $14-20$ \\
\hline \multicolumn{2}{|l|}{ Systolic blood pressure at hospital arrival $-\mathrm{mm} \mathrm{Hg}$} \\
\hline Median & 145 \\
\hline Interquartile range & $128-163$ \\
\hline ASPECTS on $\mathrm{CT}-$ median (interquartile range) ${ }^{* *}$ & $9(8-10)$ \\
\hline \multicolumn{2}{|l|}{ Location of occlusion on CTA or DSA - no./total no. (\%) } \\
\hline The M1 middle-cerebral-artery segment & 13/15(86.7) \\
\hline Ipsilateral cervical carotid occlusion — no. (\%) & 2/15(13.3) \\
\hline \multicolumn{2}{|l|}{ Stroke onset to the emergency } \\
\hline Median & 165 \\
\hline Interquartile range & $115-300$ \\
\hline \multicolumn{2}{|l|}{ Stroke onset to study CT } \\
\hline Median & 185 \\
\hline Interquartile range & $145-340$ \\
\hline \multicolumn{2}{|l|}{ Study $C T$ to groin puncture } \\
\hline Median & 45 \\
\hline Interquartile range & $38-60$ \\
\hline \multicolumn{2}{|l|}{ Study CT to first reperfusion+† } \\
\hline Median & 90 \\
\hline Interquartile range & $65-110$ \\
\hline
\end{tabular}

*The intervention group of thrombectomy was assigned to endovascular treatment by solitaire stnet.CT denotes computed tomography, CTA CT angiography, ICA internal carotid artery, and IV intravenous.

₹ Scores on National Institutes of Health Stroke Scale (NIHSS) range from 0 to 42, with higher scores indicating more severe neurologic deficits.

** The Alberta Stroke Program Early Computed Tomography Score (ASPECTS) is an imaging measure of the extent of ischemic stroke. Scores ranges from 0 to 10 , with higher scores indicating a smaller infarct core (details are available at www.aspectsinstroke.com).

t† First reperfusion was defined as the first visualization of reflow in the middle cerebral artery, usually on deployment of a retrievable stent. 


\section{Results}

\section{Typical cases}

Recanalization images from 3 cases are presented in Figure $1 \sim 3$. The preoperative $\mathrm{TICl}$ grading of these 15 patients were all level 0 . After the thrombectomy, 14 patients were level $2 \mathrm{~b}$ to level 3. However one ipsilateral cervical carotid occlusion patient demonstrated failure to recanalization.

\section{The clinical outcome}

Fourteen patients with reperfusion at 24 hours and showed good early neurologic improvement. The MRS score of all 14 patients was $<2$ point at 90 days. There were no obvious adverse reactions and complications in these patients after mechanical thrombectomy. Primary and secondary efficacy outcomes are shown at Table 2.

\section{Discussion}

The new intracranial solitaire stent has good plasticity, handling, intraoperative releasing, and can be recycled again. The solitaire stent support side is completely open, has a closed and openmesh design simultaneously to ensure good transmission capacity and high radial support $[8,9]$. Based on the characteristics of the solitaire, the stent can be used for adjuvant embolization of intracranial aneurysms, but in recent years, solitaire stents were used more for intracranial large artery occlusion in patients with acute cerebral infarction, especially more than thrombolytic therapy time window, thrombolysis treatment failure, or patients with thrombolysis taboo. Solitaire stents coupled with thrombolytic drugs, can significantly improve the rate of recanalization, especially at the large end of the internal carotid artery, middle cerebral artery. Vascular thrombosis or embolism curative effects are improved. In PascalP's study, none of the patients with an MRI ASPECTS $\geq 7$ or a CTASPECTS $\geq 6$ on pretreatment imaging reached a favorable outcome [10]. But sometimes, CTASPECTS are almost 10, MRI ASPECTS $\leq 5$, like our patient 3 . We also performed the thrombectomy and got good clinical outcomes; the NIHSS score was 1 at 90 days.
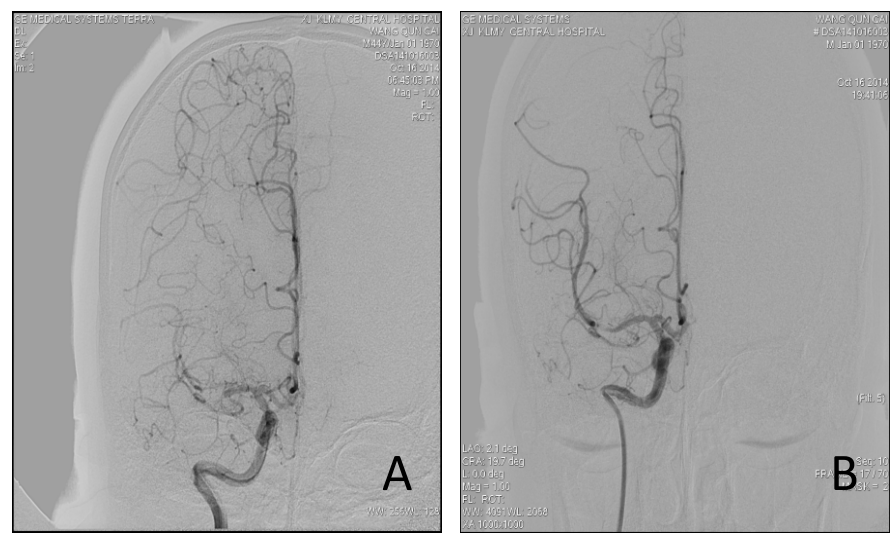

Figure 1. Patient 1:The MCA M1 occlusive images before and after treatment .In 1a, preoperative DSA imagine is shown on the right side of the MCA M1 occlusion .In 1b, solitaire stent thrombosis after immediate review imaging, the right MCA show stotally recanalization and the TIMI grade was3.
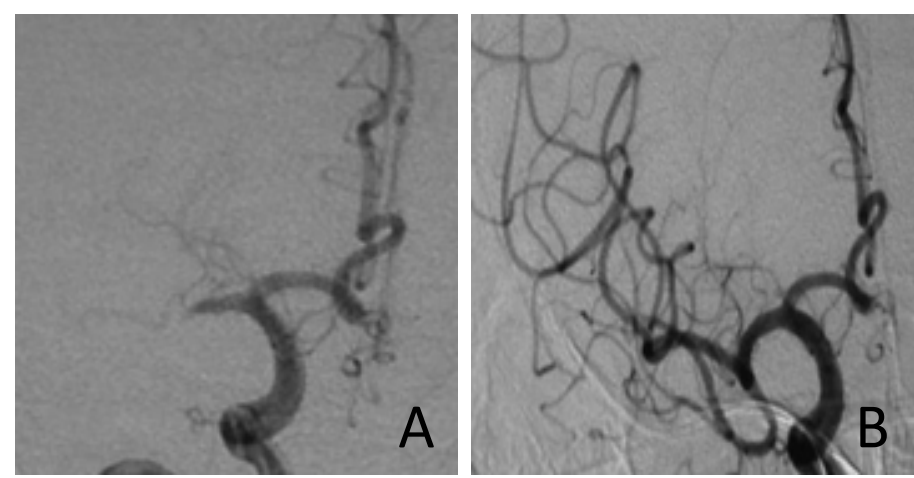

Figure 2. Patient 2 :The MCA M1 occlusive images before and after treatment. In 2a,preoperative DSA imagine is shown on the right side of MCA M1 occlusion . In 2b,imagine displays that the MCA completely was recanalizated.
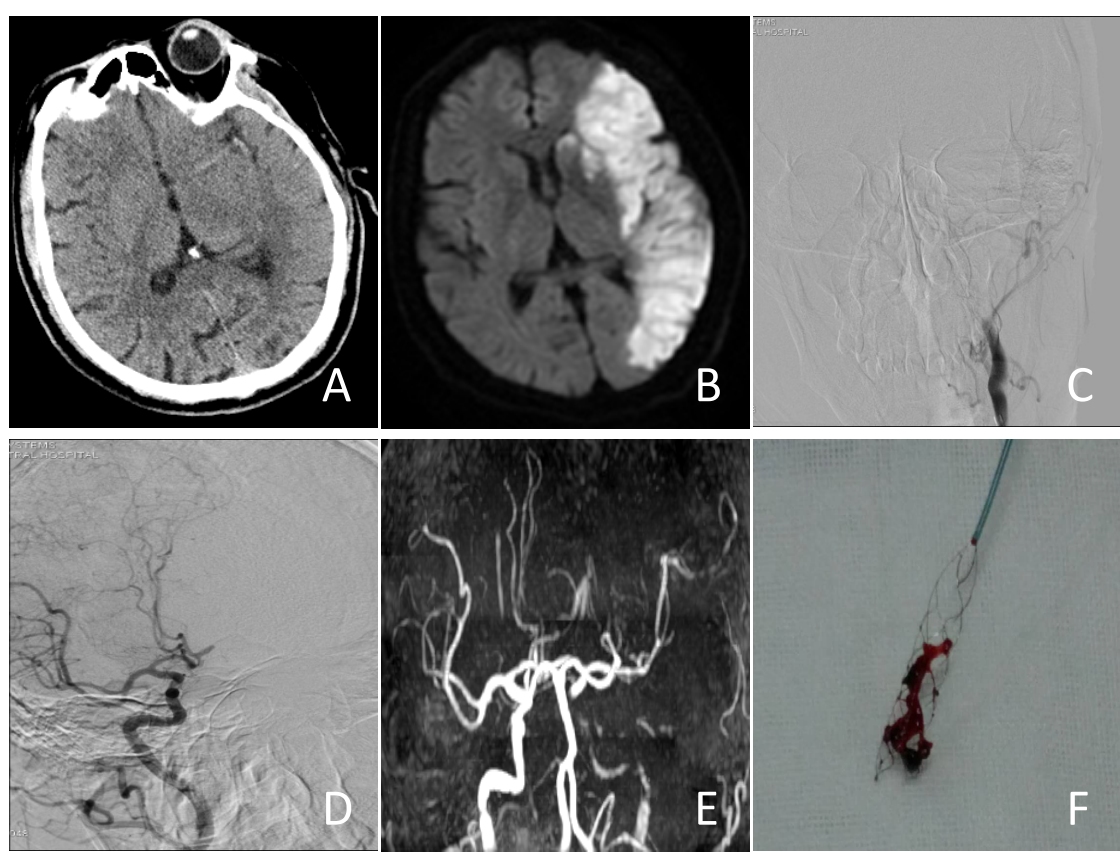

Figure 3. Patient 3:A wake upstroke patient who suffered from internal carotid arteryocclusion. In 3a,it is shown that a high density sign covered on the light side ofMCA. In $3 \mathrm{~b}$, the DWI showed the acute ischemic stroke of the left MCA after one day. In $3 c$ and 3d, the DSA images show the left interal carotid artery occlusion. In 3e,the left MCA shows complete recanalization after the thrombectomy, and the clot could be seen in $3 f$. 
Incidence for the end of the event and determine recanalization of $\mathrm{TICl}$ classification standard and a large, prospective, multicenter, randomized, controlled study of SWIFT consistent [11], several studies have shown that stent supports bolt extraction for treatment of acute cerebral infarction caused by artery occlusion, specific and effective rate of blood vessels, can effectively save in ischemia half dark band of tissue cells, improve the clinical outcomes for patients with malignant cerebral infarction [12-15], preoperative diffusion and perfusion imaging, judging ischemia half the size of the dark band, and also carries on intravascular should decide whether the important basis [16,17]. A large meta-analysis showed that intravenous thrombolysis of the great vessels take rate less than $30 \%$, however stents should be used to achieve $\mathrm{TICI}$ block blood vessels - 3 level was $93.3 \%$, the rate of over 90 days [18].

The patient 1 in postoperative patients with middle cerebral artery stenosis, M1 segment on the research report further used the balloon dilatation, and obtained the good blood flow and clinical prognosis [19]. Although mechanical bolt can significantly improve the rate of recanalization, it also has the risk of symptomatic intracranial hemorrhage. Postoperative literature reports a hemorrhage rate of $0 \%$ 4\% [20].

In patient 3, because of the vascular circuity and ipsilateral cervical carotid occlusion,

Table 2. Primary and Secondary Efficacy Outcomes*.

\begin{tabular}{lc}
\hline Outcome & $\begin{array}{c}\text { Thrombectomy } \\
(\mathbf{N}=15)\end{array}$ \\
\hline Primary outcome & $14 / 15(93 \%)$ \\
TICl score of $2 \mathrm{~b}$ or 3 at final angiogram - no./total no. (\%)† & $5(3-14)$ \\
NIHSS score at 24 hours - median (interquartile range) & \\
Secondary Outcome & $14 / 15(93 \%)$ \\
NIHSS score of 0-2 at 90 days - no./total no. (\%) & $14 / 15(93 \%)$ \\
Modified Rankin score of 0-2 at 90 days - no./total no. (\%) & $2(1-7)$ \\
\hline NIHSS score at 90 days - median (interquartile range)
\end{tabular}

* The primary analysis involved 15 the intervention patients of thrombectomy. Scores on the modified Rankin scale of functional disability range from 0 (no symptoms) to 6 (death).

† A Thrombolysis in Cerebral Infarction (TICI) score of $2 \mathrm{~b}$ or 3 indicates successful reperfusion

we adopted the method of combining the solitaire stent with penumbra system for recanalization. Penumbra's constant pressure suction system, can reduce the occurrence of intraoperative blood clots to distal displacement. But due to its low radial support, reaching the thrombus catheter is relatively difficult, in practice it is often necessary to perform catheter coaxial technology, which is not only expensive surgery but also results in longer operating times. Strudel stent has easier circuity and bifurcation by blood vessels, and the operation cost is low, but prone to thrombosis shift towards the far end. Therefore, combining penumbra system and apple strudel stents, takes advantages of each of the benefits of the respective systems; more quickly place the stent catheter, and reduce thrombus fragments distal displacement events.

In conclusion, the application of mechanical thrombectomy with Solitaire stent in the treatment of acute ischemic stroke with large cerebral artery occlusion is safe and time-efficient, which could improve the recanalization rate, decrease or even eliminate the application of thrombolytic drugs and reduce the rate of intracranial hemorrhage. Wake up stroke patients can also benefit from thrombectomy. However, this study is a single arm prospective clinical study with a relative small sample size. Without a control group, conclusions should be further confirmed by large prospective multicenter randomized clinical trials.

\section{References}

[1] Mozaffarian D, Benjamin EJ, Go AS, Arnett DK, Blaha MJ, Cushman M. American Heart Association Statistics Committee and Stroke Statistics Subcommittee. Heart disease and stroke statistics-2015 update: a report from the American Heart Association. Circulation. 2015; 131:e29-e322.

[2] Berkhemer OA, Fransen PS, Beumer $D$, van den Berg LA, Lingsma HF, Yoo AJ, Schonewille WJ, Vos JA, Nederkoorn PJ, Wermer MJ, van Walderveen MA, Staals J, Hofmeijer J, van Oostayen JA, Lycklama a Nijeholt GJ, Boiten J, Brouwer PA, Emmer BJ, de Bruijn SF, van Dijk LC, Kappelle LJ, Lo RH, van Dijk EJ, de Vries J, de Kort PL, van Rooij WJ, van den Berg JS, van Hasselt BA, Aerden LA, Dallinga RJ, Visser MC, Bot JC, Vroomen PC, Eshghi O, Schreuder TH, Heijboer RJ, Keizer K, Tielbeek $A V$, den Hertog HM, Gerrits DG, van den Berg-Vos RM, Karas GB, Steyerberg EW, Flach $\mathrm{HZ}$, Marquering HA, Sprengers ME, Jenniskens
SF, Beenen LF, van den Berg R, Koudstaal PJ, van Zwam WH, Roos YB, van der Lugt $A$, van Oostenbrugge RJ, Majoie CB, Dippel DW and Investigators MC. A randomized trial of intraarterial treatment for acute ischemic stroke. N Engl J Med 2015; 372: 11-20.

[3] Saver JL, Goyal M, Bonafe A, Diener HC, Levy El, Pereira VM, Albers GW, Cognard C, Cohen DJ, Hacke W, Jansen O, Jovin TG, Mattle HP, Nogueira RG, Siddiqui AH, Yavagal DR, Baxter BW, Devlin TG, Lopes DK, Reddy VK, du Mesnil de Rochemont R, Singer OC, Jahan R and Investigators SP. Stent-retriever thrombectomy after intravenous t-PA vs. t-PA alone in stroke. N Engl J Med 2015; 372: 2285-2295.

[4] Liebig T, Reinartz J, Hannes R, Miloslavski Eand Henkes H.Comparative in vitro study of five mechanical embolectomy systems: effectiveness of clot removal and risk of distal embolization. Neuroradiology 2008; 50: 43-52. 
[5] Smith WS, Sung G, Saver J, Budzik R, Duckwiler G, Liebeskind DS, Lutsep HL, Rymer MM, Higashida RT, Starkman S, Gobin YP, Multi MI, Frei D, Grobelny T, Hellinger F, Huddle D, Kidwell C, Koroshetz W, Marks M, Nesbit G and Silverman IE. Mechanical thrombectomy for acute ischemic stroke: final results of the Multi MERCI trial. Stroke 2008; 39: 1205-1212.

[6] Goyal M, Demchuk AM, Menon BK, Eesa M, Rempel JL, Thornton J, Roy D, Jovin TG, Willinsky RA, Sapkota BL, Dowlatshahi D, Frei DF, Kamal NR, Montanera WJ, Poppe AY, Ryckborst KJ, Silver FL, Shuaib A, Tampieri D, Williams D, Bang OY, Baxter BW, Burns PA, Choe H, Heo JH, Holmstedt CA, Jankowitz B, Kelly M, Linares G, Mandzia JL, Shankar J, Sohn SI, Swartz RH, Barber PA, Coutts SB, Smith EE, Morrish WF, Weill A, Subramaniam S, Mitha AP, Wong JH, Lowerison MW, Sajobi TT, Hill MD and Investigators ET. Randomized assessment of rapid endovascular treatment of ischemic stroke. N Engl J Med 2015; 372: 1019-1030.

[7] Smith WS. Safety of mechanical thrombectomy and intravenous tissue plasminogen activator in acute ischemic stroke. Results of the multi Mechanical Embolus Removal in Cerebral Ischemia (MERCI) trial, part I. AJNR Am J Neuroradiol 2006; 27: 1177-1182.

[8] Natarajan SK, Siddiqui AH, Hopkins LN and Levy El. Retrievable, detachable stent-platform-based thrombectomy device (Solitaireg ${ }^{\text {TM }}$ FR) for acute stroke revascularization: First demonstration of feasibility in a canine stroke model. Vascular Disease Management 2010; 7:

[9] Jahan R. Solitaire flow-restoration device for treatment of acute ischemic stroke: safety and recanalization efficacy study in a swine vessel occlusion model. AJNR Am J Neuroradiol 2010; 31: 1938-1943.

[10] Gratz PP, Jung S, Schroth G, Gralla J, Mordasini P, Hsieh K, Heldner MR, Mattle HP, Mono ML, Fischer U, Arnold M and Zubler C. Outcome of standard and high-risk patients with acute anterior circulation stroke after stent retriever thrombectomy. Stroke 2014; 45: 152-158.

[11] Saver JL, Jahan R, Levy El, Jovin TG, Baxter B, Nogueira R, Clark W, Budzik R, Zaidat $\mathrm{OO}$ and Trialists S. SOLITAIRE with the intention for thrombectomy (SWIFT) trial: design of a randomized, controlled, multicenter study comparing the SOLITAIRE Flow Restoration device and the MERCI Retriever in acute ischaemic stroke. Int J Stroke 2014; 9: 658-668.

[12] Castro-Afonso LH, Abud TG, Pontes-Neto OM, Monsignore LM, Nakiri GS, Cougo-Pinto PT, Oliveira L, Santos D, Dias FA, Fabio SC, Coletto
FA and Abud DG. Mechanical thrombectomy with solitaire stent retrieval for acute ischemic stroke in a Brazilian population. Clinics (Sao Paulo) 2012; 67: 1379-1386.

[13] Castano C, Dorado L, Guerrero C, Millan M, Gomis M, Perez de la Ossa N, Castellanos M, Garcia MR, Domenech S and Davalos A. Mechanical thrombectomy with the Solitaire $A B$ device in large artery occlusions of the anterior circulation: a pilot study. Stroke 2010; 41: 1836-1840.

[14] Yoon YH, Yoon W, Jung MY, Yim NY, Kim BC and Kang HK. Outcome of mechanical thrombectomy with Solitaire stent as first-line intraarterial treatment in intracranial internal carotid artery occlusion. Neuroradiology 2013; 55: 999-1005.

[15] Mokin M, Dumont TM, Veznedaroglu E, Binning MJ, Liebman KM, Fessler RD, 2nd, To CY, Turner RDt, Turk AS, Chaudry MI, Arthur AS, Fox BD, Hanel RA, Tawk RG, Kan P, Gaughen JR, Jr., Lanzino G, Lopes DK, Chen M, Moftakhar R, Billingsley JT, Ringer AJ, Snyder KV, Hopkins LN, Siddiqui $\mathrm{AH}$ and Levy El. Solitaire Flow Restoration thrombectomy for acute ischemic stroke: retrospective multicenter analysis of early postmarket experience after FDA approval. Neurosurgery 2013; 73: 19-25; discussion 25-16.

[16] Costalat V, Machi P, Lobotesis K, Maldonado I, Vendrell JF, Riquelme C, Mourand I, Milhaud D, Heroum C, Perrigault PF, Arquizan C and Bonafe A. Rescue, combined, and stand-alone thrombectomy in the management of large vessel occlusion stroke using the solitaire device: a prospective 50-patient single-center study: timing, safety, and efficacy. Stroke 2011; 42: 1929-1935.

[17] Davalos A, Pereira VM, Chapot R, Bonafe A, Andersson T, Gralla J and Solitaire G. Retrospective multicenter study of Solitaire FR for revascularization in the treatment of acute ischemic stroke. Stroke 2012; 43: 2699-2705.

[18] Seners P, Turc G, Maier B, Mas JL, Oppenheim C and Baron JC. Incidence and Predictors of Early Recanalization After Intravenous Thrombolysis: A Systematic Review and Meta-Analysis. Stroke 2016; 47: 2409-2412.

[19] Park JH, Park SK, Jang KS, Jang DK and Han YM. Critical use of balloon angioplasty after recanalization failure with retrievable stent in acute cerebral artery occlusion. Journal of Korean Neurosurgical Society 2013; 53: 77-82.

[20] Novakovic RL, Toth G, Narayanan S and Zaidat OO. Retrievable stents, "stentrievers," for endovascular acute ischemic stroke therapy. Neurology 2012; 79: S148-157. 